\title{
Alpha-Amylase Inhibitory Effect and Docking Studies of Some New Curcumin-Triazole Derivatives
}

\section{Eman Elattar, Amal A Galala, Hassan-Elrady A Saad and Farid A Badria*}

Department of Pharmacognosy, Faculty of Pharmacy, Mansoura University, Egypt

*Corresponding Author: Farid A Badria, Department of Pharmacognosy, Faculty of Pharmacy, Mansoura University, Egypt.

Received: September 26, 2019; Published: October 14, 2019

DOI: $10.31080 /$ ASNH.2019.03.0503

\section{Abstract}

Curcumin was used as a starting scaffold to design three new triazole derivatives. The synthesis of these triazoles was performed using the $\mathrm{Cu}(\mathrm{I})$-catalyzed azide-alkyne 1,3-dipolar cycloaddition (CuAA) click reaction. The structures of the prepared triazoles have been determined on the basis of NMR spectroscopy and other spectroscopic methods. Curcumin (C1) and its triazole derivatives (C2, C3 and C4) were tested in terms of alpha-amylase inhibition potency, which is an essential metabolic enzyme for carbohydrate metabolism. Curcumin-benzyl triazole derivative C2 showed effective inhibitory activity against alpha-amylase (83.9\% inhibition at concentration $1 \mathrm{mg} / \mathrm{ml}$ ). Molecular docking studies was also performed to predict the binding affinity of the prepared triazoles toward human $\alpha$-amylase (PDBID: 1u30).

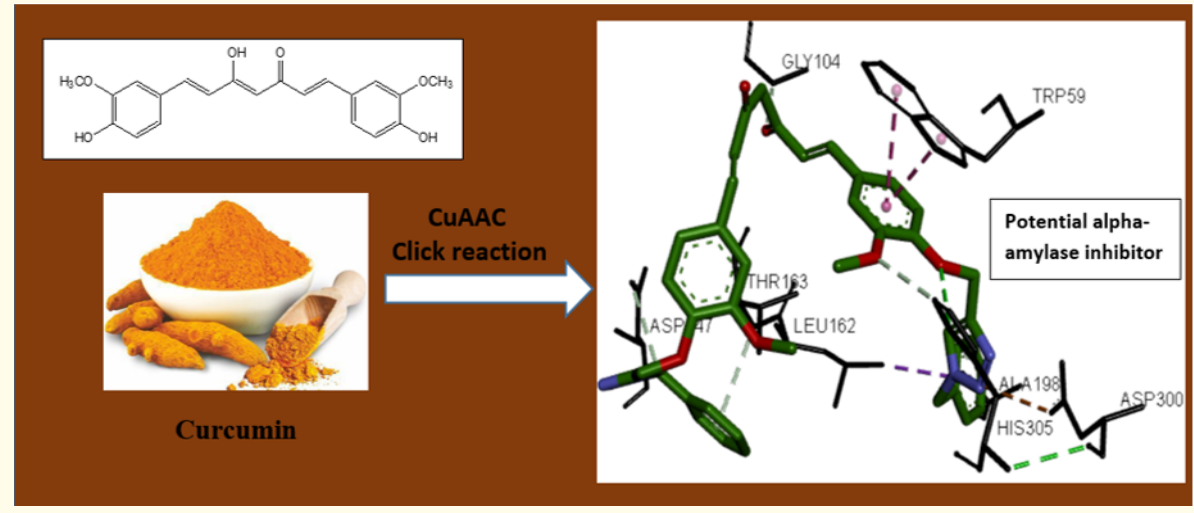

Keywords: Curcumin; Triazole; $\alpha$-Amylase; Click Chemistry; Azide-Alkyne Cycloaddition

\section{Introduction}

Throughout history, natural products were used to treat various human diseases [1]. The exploitation of natural product has also been extended for commercial purposes to refer to cosmetics, and foods produced from natural sources. Natural products have continued to play a crucial role in many drug development and research programs, due to their wide range of structural diversity and novel mechanisms of action [2].

Many natural products have been chemically or biologically modified to produce analogues with significant therapeutic values. Many useful analogues that exhibited very promising applications as enzyme(s) inhibitors and potential therapeutic agents were successfully designed, for example; methyl eugenol analogues as anti-tubulin agents for breast cancer [3], betulinic acid analogues as potent topoisomerase I and II alpha inhibitors [4], glycyrrhetin- ic acid analogues as a selective anti-Alzheimer agent with remarkable acetylcholinesterase inhibitory activity [5], gingerol analogues as Leukotriene A4 hydrolase inhibitors for colorectal cancer treatment [6], curcumin analogues as antitumor agents [7].

However, emerging $\mathrm{Cu}(\mathrm{I})$-catalyzed azide-alkyne 1,3-dipolar cycloaddition (CuAAC), popularly known as the "click reaction", serves as the most powerful tool for facile construction of simple to complex architectures under mild conditions. Click-knitted threads of two exclusively different molecular entities have created some really interesting structures with a broad spectrum of applicability, As reaction products of $\mathrm{CuAAC}, 1,2,3$ triazoles are attractive constructs of target molecules due to their wide range of biological properties, such as antimicrobial, antitubercular, antimalarial, anticancer, and antioxidant activity [8]. 
Diabetes mellitus as a complex metabolic disorder is related with impaired insulin secretion, which leads to hyperglycemia (high levels of blood glucose), inflammation and oxidative damage [9]. $\alpha$-amylase and $\alpha$-glucosidase are key enzymes involved in the metabolism of carbohydrates and intestinal absorption. The breakdown of carbohydrates can be retarded by inhibiting the $\alpha$ amylase enzyme. Therefore, inhibitors of $\alpha$ - amylase play a pivotal role in preventing carbohydrates digestion and result in lowering blood glucose levels [10]. Acarbose, voglibose and other known $\alpha$-amylase inhibitors $\alpha$-amylase used for treatment of diabetes were reported to have some gastrointestinal adverse effects such as diarrhea $[11,12]$. So, there is a plentiful interest for development of new alternative $\alpha$-amylase inhibitors [13].

Curcumin is an orange-yellow polyphenol substance of turmeric (Curcuma species), Turmeric is a natural rhizome that is used worldwide as a spice in a wide variety of food. It is known to have a vital role against pathological conditions such as cancer, oxidative damage, inflammation, atherosclerosis, and neurodegenerative diseases. Curcumin is also been demonstrated to be a potent inhibitor of nuclear factor-kappaB, lipooxygenase, cyclooxygenase-2 [14].

Thereby, this work aimed to design new 1,2,3 triazole based molecules from a natural starting material (curcumin) using click chemistry and to evaluate their in-vitro $\alpha$-amylase inhibitory potency. In addition to this, we have also performed docking studies for the synthesized compounds.

\section{Materials and Methods}

General experimental procedures: Melting points were determined on Stuart ${ }^{\circledR}$ melting point apparatus model SMP10 and are uncorrected. ${ }^{1} \mathrm{H}$ - and ${ }^{13} \mathrm{C}-\mathrm{NMR}$ spectra were obtained using JOEL ECA II 500 and BRUKER Avance III 400 spectrometer (Bruker AG, Switzerland). Chemical shifts $(\delta)$ are reported in ppm relative to the solvent signal and coupling constants are given in $\mathrm{Hz}$. IR spectra were obtained using a Thermo Scientific Nicolet ${ }^{\mathrm{TM}}$ iS $^{\mathrm{TM}} 10$ FTIR spectrometer instrument. The reactions progress and the final products purity were observed by thin layer chromatography (TLC) that is performed on precoated silica gel $60 \mathrm{GF}_{254}(0.2 \mathrm{~mm}$ thick) on aluminum sheets (Merck, Germany). Column chromatography was carried out on silica gel G 60-230 mesh (Merck, Germany). All organic solvents used were distilled.

\section{Chemicals}

Alpha-amylase from Aspergillus oryzae, curcumin, propargyl bromide, benzylazide, methyl 2-azidoacetate and 4-azidoacetophenone (Sigma Aldrich, USA), 3,5-dinitrosalicylic acid color reagent (DNS, Euromedex, France), All solvents and chemicals were of analytical grade.

\section{Preparation of di-alkyne curcumin}

Di-alkyl curcumin was prepared using a similar procedure that described in the previous literature [15] using potassium carbonate (3.5 eq.) and propargyl bromide (1.3 eq.), refluxing at $80^{\circ} \mathrm{C}$ for $48 \mathrm{hr}$. and extracting the crude product into ethyl acetate. The crude product was purified by column chromatography on silica gel. It was eluted with petroleum ether-ethyl acetate $(88: 12 \mathrm{v} / \mathrm{v})$ as the major reaction product ( $100 \mathrm{mg}, 66.7 \%$ yield). It was obtained as orange-yellow powder. TLC: $\mathrm{Rf}=0.38$ (dicloromethane $100 \%$ ). The IR spectrum of the compound exhibited peaks characteristic of the curcumin terminal acetylene moiety at $3247 \mathrm{~cm}-1$ (CH stretch of $\mathrm{C} \equiv \mathrm{C}-\mathrm{H})$, and $2124 \mathrm{~cm}-1$ (-C $\equiv \mathrm{C}$ - stretch) confirming the formation of terminal alkyne.

\section{Preparation and purification of curcumin derivatives}

Preparation and purification of curcumin-benzyl triazole C2

A mixture of $\mathrm{CuSO}_{4} .5 \mathrm{H}_{2} \mathrm{O}(0.15$ eq., $2.7 \mathrm{mg}$ ), ascorbic acid $(0.45$ eq., $5.7 \mathrm{mg}$ ) and benzyl azide $(11 \mu \mathrm{l})$ were mixed in distilled water $(5 \mathrm{~mL})$ and adding the resultant solution to the mixture of alkynecurcumin $(30 \mathrm{mg})$ in methylene chloride $(5 \mathrm{~mL})$. The mixture was stirred with a magnetic stirrer bar for $24 \mathrm{hr}$. at room temperature. The reaction was monitored by TLC [silica gel, pet ether: ethyl acetate (1:1)]. The reaction mixture was filtered to obtain orange powder $(8 \mathrm{mg})$. The reaction mixture was then extracted into ethyl acetate $(3 \times 5 \mathrm{ml})$. The ethyl acetate extract was evaporated to obtain crude micture $(25 \mathrm{mg}$ ). The crude reaction mixture was chromatographed over a silica gel column. Compound C2 (15mg) was eluted with $60 \%$ ethyl acetate in pet ether. It was obtained as orange powder, Rf: 0.25, TLC system: pet ether: ethyl acetate (1:1).

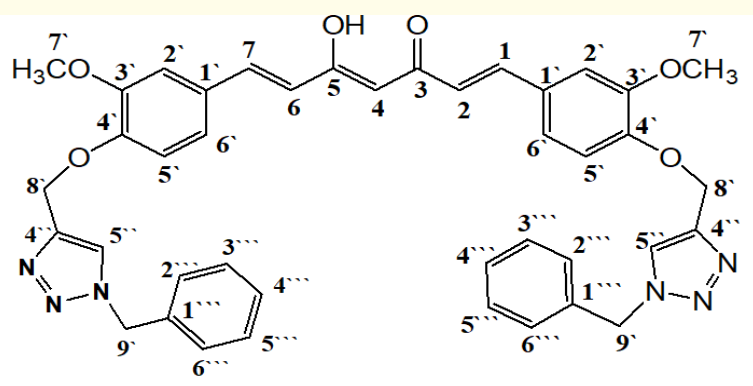

Curcumin-benzyl triazole $\mathbf{C} 2$.

Preparation and purification of curcumin-methylacetate triazole (C3) and curcumin- acetophenone triazole (C4)

These compounds were prepared using a similar procedure to that described for the preparation of compound C2. The azide corresponded to Methyl 2-azidoacetate, 4-azidoacetophenone, respectively. Curcumin-methylacetate triazole C3 (10 mg) was eluted with 
pet ether: ethyl acetate (1:1). It was obtained as orange-yellow powder, Rf: 0.35, TLC system: dichloromethane: ethylacetate (1:1). Curcumin- acetophenone triazole C4 (9 mg) was eluted with pet ether: ethyl acetate (1:1). It was obtained as orange-yellow powder, Rf: 0.37, TLC system: dichloromethane: ethylacetate (1:1).<smiles></smiles>

Curcumin-methylacetate triazole C3.

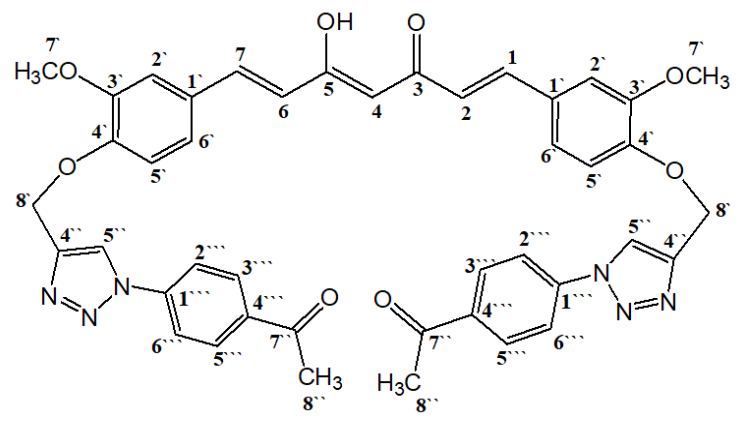

Curcumin-methylacetate triazole C4.

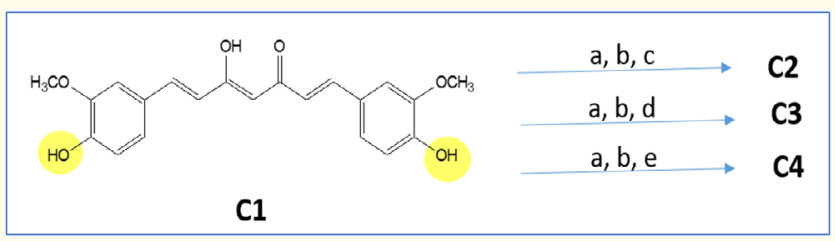

Scheme S1: Synthesis of curcumin derivatives C2-C4

- Propargyl bromide, acetone $80^{\circ} \mathrm{C}, 48 \mathrm{hr}$.

- Distilled water: dichloromethane (1:1), $\mathrm{CuSO}_{4} \cdot 5 \mathrm{H}_{2} \mathrm{O}, 0.15$ equiv., ascorbic acid, 0.45 equiv., rt., $24 \mathrm{hr}$.

- Benzyl azide.

- $\quad$ Methyl 2-azidoacetate

- 4-azidoacetophenone.

Amylase inhibitory activity

The prepared triazoles have been evaluated for their alphaamylase inhibitory activity using frequently used standard method [16].

\section{Docking studies}

A Library of compounds was constructed using molecular operation environment software (MOE software), The prepared triazoles as well as curcumin parent compound were docked in the $\alpha$-amylase binding site (protein data bank ID: $1 \mathrm{u} 30$ ) using stan- dard docking protocol in iGemDock software. Doking studies predicted the total energy required for binding and consensus scoring based on the ability of compounds to interact with essential amino acids residues in the active site (Pharma score). Poses (the relative orientation of ligand to a protein) were visualized using Discovery studio ligand interaction visualizer [17].

\section{Results and Discussion \\ Chemistry}

The structure of compound $\mathrm{C} 1$ was characterized as $(1 \mathrm{E}, 6 \mathrm{E}) 1,7-$ bis-(4-hydroxy-3-methoxyphenyl)-1,6-heptadiene-3,5-dione (curcumin) by comparing its spectroscopic data with the previous literature (Lestari and Indrayanto, 2014).

1H-NMR of compound C2 (Table 1) showed signals for 10 aromatic proton at $\delta 7.35$ to $7.38(5 \mathrm{H}, \mathrm{m})$ in addition to two methylene groups at $\delta 5.30(4 \mathrm{H}, \mathrm{s})$ indicating presence of two benzyl moieties. A singlet signal at $\delta 7.57\left(2 \mathrm{H},=\mathrm{CH}-\right.$ triazole, $\left.\mathrm{H}-5^{\prime \prime}\right)$ assigned for two methine protons of tow triazole rings suggesting successful click reaction. ${ }^{13} \mathrm{C}$-NMR spectrum showed signals at $\delta$ $62.9\left(\mathrm{O}-\mathrm{CH}_{2}\right.$, methylene bridge between the functional group of curcumin and the azide) and $\delta 54.4\left(\mathrm{~N}-\mathrm{CH}_{2}\right)$. On the basis of these evidences, the structure of compound $\mathrm{C} 2$ was determined to be the new compound (1E,6E)1,7-bis-[4-(1-Benzyl-1H-[1,2,3]triazol4-ylmethoxy)-3-methoxyphenyl]-1,6-heptadiene-3,5-dione.

\begin{tabular}{|c|c|c|}
\hline Atom No. & $\begin{array}{c}{ }^{13} \text { C-NMR Chemical shift } \\
(\delta)\end{array}$ & $\begin{array}{c}{ }^{1} \mathrm{H}-\mathrm{NMR} \text { Chemical shift } \\
(\delta)\end{array}$ \\
\hline \multicolumn{3}{|c|}{ 1,6-heptadiene-3,5-dione moiety } \\
\hline 1,7 & 140.2 & $7.58(2 \mathrm{H}, \mathrm{d}, J=15.5 \mathrm{~Hz})$ \\
\hline 2,6 & 122.2 & $6.49(2 \mathrm{H}, \mathrm{d}, J=16.0 \mathrm{~Hz})$ \\
\hline 3,5 & 183.0 & -- \\
\hline 4 & 101.3 & $5.82(1 \mathrm{H}, \mathrm{s})$ \\
\hline \multicolumn{3}{|c|}{ bis-(4-hydroxy-3-methoxyphenyl) moiety } \\
\hline 1 & -- & -- \\
\hline 2 & 110.3 & \multirow{5}{*}{$\begin{array}{c}\text { 6.98- } 7.12(6 \mathrm{H}, \mathrm{m}, \\
\left.\mathrm{H} 2^{\prime} / 5^{`} / 6^{\prime}\right)\end{array}$} \\
\hline 3 & 149.5 & \\
\hline 4 & 149.6 & \\
\hline $5 `$ & 113.7 & \\
\hline $6{ }^{\prime}$ & 122.4 & \\
\hline $\mathrm{OCH}_{3}$ & 55.9 & $3.88(6 \mathrm{H}, \mathrm{s})$ \\
\hline \multicolumn{3}{|c|}{ Two triazole rings } \\
\hline $4 "$ & -- & -- \\
\hline $5 "$ & 123.0 & $7.57(2 \mathrm{H}, \mathrm{s})$ \\
\hline \multicolumn{3}{|c|}{ Two phenyl rings of azido benzyl moieties } \\
\hline $1^{\prime \prime}$ & 134.2 & -- \\
\hline $2 \cdots, 6^{\prime \prime}$ & 129.1 & \multirow[t]{3}{*}{ 7.35- $7.38(10 \mathrm{H}, \mathrm{m})$} \\
\hline $3^{\cdots,}, 5^{\cdots}$ & 128.2 & \\
\hline $4 \cdots$ & 128.9 & \\
\hline \multicolumn{3}{|c|}{ Methylene bridges } \\
\hline $\mathrm{N}-\mathrm{CH}_{2}$ & 54.3 & $5.30(4 \mathrm{H}, \mathrm{s})$ \\
\hline $7 ` \mathrm{O}-\mathrm{CH}_{2}$ & 62.9 & $5.51(4 \mathrm{H}, \mathrm{s})$ \\
\hline
\end{tabular}

Table 1: ${ }^{1} \mathrm{H}-\mathrm{NMR}$ and ${ }^{13} \mathrm{C}$-NMR spectra of curcumin-benzyl triazole $\mathbf{C 2}^{\mathrm{a}}$.

${ }^{\mathrm{a}}$ In $\left(\mathrm{CDCL}_{3}\right)$, at $500 \mathrm{MHz}$ for ${ }^{1} \mathrm{H}-\mathrm{NMR}$, at $125 \mathrm{MHz}$ for ${ }^{13} \mathrm{C}-\mathrm{NMR}$, Coupling constants (U) are in $\mathrm{Hz}$. 
${ }^{1} \mathrm{H}-\mathrm{NMR}$ spectal data of compound C3 (Table 2) displayed proton signals at $\delta 5.11\left(4 \mathrm{H}, \mathrm{s}, \mathrm{NCH}_{2}, 2\right.$ '”) for two identical methylene bridges neighboring $\mathrm{N}-1$ " of triazole moiety. Appearance of proton signal at $\delta\left(2 \mathrm{H}, \mathrm{s}, 5^{\prime \prime}\right)$ for two methine protons indicating the formation of triazole rings which was further confirmed by the presence of carbon signals at $\delta 124.5$ (C-5”) for methine carbon of triazole ring. Appearance of singlet signal at $\delta 5.29\left(4 \mathrm{H}, \mathrm{s}, \mathrm{OCH}_{2}\right)$ revealed the presence of two methylene bridges. APT spectrum of compound C3 displayed carbon signals at $\delta 62.9\left(\mathrm{OCH}_{2}\right)$ assigned for two methylene bridges confirming the successful junctions of di-alkyne curcumin with two methyl 2- azidoacetate moieties. Hence, compound C3 was concluded to be the new compound, [4-(1E,6E)1,7-bis-3-methoxy-phenoxymethyl-1,6-heptadiene-3,5dione $[1,2,3]$ triazol-1-yl]-acetic acid methyl ester.

\begin{tabular}{|c|c|c|}
\hline Atom No. & $\begin{array}{l}\text { APT Chemical shift } \\
\qquad(\delta)\end{array}$ & $\begin{array}{c}{ }^{1} \mathrm{H}-\mathrm{NMR} \text { Chemical shift } \\
(\delta)\end{array}$ \\
\hline \multicolumn{3}{|c|}{ 1,6-heptadiene-3,5-dione moiety } \\
\hline 1,7 & 140.3 & $7.52(2 \mathrm{H}, \mathrm{d}, J=15.6 \mathrm{~Hz})$ \\
\hline 2,6 & 122.3 & $6.43(2 \mathrm{H}, \mathrm{d}, J=16.0 \mathrm{~Hz})$ \\
\hline 3,5 & 183.2 & -- \\
\hline 4 & 101.4 & $5.76(1 \mathrm{H}, \mathrm{s})$ \\
\hline \multicolumn{3}{|c|}{ bis-(4-hydroxy-3-methoxyphenyl) moiety } \\
\hline 1 & 128.9 & -- \\
\hline 2 & 110.4 & \multirow{5}{*}{$\begin{array}{c}7.01-7.14(6 \mathrm{H}, \mathrm{m}, \\
\left.\mathrm{H} 2^{\prime} / 5^{\prime} / 6^{\prime}\right)\end{array}$} \\
\hline 3 & -- & \\
\hline 4 & 147.8 & \\
\hline 5 & 113.7 & \\
\hline 6 & 117.8 & \\
\hline $3^{\prime}-\mathrm{OCH}_{3}$ & 55.9 & $3.85(6 \mathrm{H}, \mathrm{s})$ \\
\hline \multicolumn{3}{|c|}{ Two triazole rings } \\
\hline $4 "$ & -- & -- \\
\hline $5 "$ & 124.5 & $7.74(2 \mathrm{H}, \mathrm{s})$ \\
\hline \multicolumn{3}{|c|}{ Two acetic acid methyl ester moieties } \\
\hline $1^{\prime \prime \prime}(\mathrm{C}=0)$ & 166.6 & -- \\
\hline $2 \cdots\left(\mathrm{N}-\mathrm{CH}_{2}\right)$ & 50.8 & $5.11(4 \mathrm{H}, \mathrm{s})$ \\
\hline $1{ }^{\prime \prime}-\mathrm{OCH}_{3}$ & 53.2 & $3.75(6 \mathrm{H}, \mathrm{s})$ \\
\hline \multicolumn{3}{|c|}{ Methylene bridges } \\
\hline $7 ` \mathrm{O}-\mathrm{CH}_{2}$ & 62.9 & $5.51(4 \mathrm{H}, \mathrm{s})$ \\
\hline
\end{tabular}

Table 2: ${ }^{1} \mathrm{H}-\mathrm{NMR}$ and APT spectra of curcumin-methyl-acetate triazole $\mathbf{C} \mathbf{3}^{\text {a }}$.

${ }^{\mathrm{a}}$ In ( $\mathrm{CDCL}_{3}$ ), at $400 \mathrm{MHz}$ for ${ }^{1} \mathrm{H}-\mathrm{NMR}$, at $100 \mathrm{MHz}$ for APT, Coupling constants $($ ) are in $\mathrm{Hz}$.

${ }^{1} \mathrm{H}-\mathrm{NMR}$ of compound C4 (Table 3) showed singlet signal at $\delta 5.35(4 \mathrm{H}, \mathrm{s}, \mathrm{OCH} 2)$, indicating the presence of two methylene bridges between curcumin and the two triazole rings. Presence of downfield proton signals at $\delta 7.79\left(4 \mathrm{H}, \mathrm{d}, \mathrm{J}=8.4 \mathrm{~Hz}, \mathrm{H} 2{ }^{\prime \prime} / 6^{\prime \prime}\right)$ and $\delta 8.05\left(4 \mathrm{H}, \mathrm{J}=8.4 \mathrm{~Hz}, \mathrm{H} 3{ }^{\prime \prime} / 5^{\prime \prime}\right)$ assigned for 8 aromatic pro- tons of two acetophenone moieties. In addition, appearance of the most downfield proton signal at $\delta 8.12\left(2 \mathrm{H}, \mathrm{s}, \mathrm{H}-5{ }^{`}\right)$ assigned for two methine protons of the two triazole rings, indicating a successful click reaction. APT spectrum of compound C4 displayed carbon signal at $\delta 62.8(\mathrm{OCH} 2)$ assigned for the methylene bridges. Hence, compound $\mathrm{C} 4$ was concluded to be (1E,6E)1,7-bis-4-[1-(4-acetylphenyl)-1H-[1,2,3]triazol-4-ylmethoxy)-3methoxyphenyl]-1,6heptadiene-3,5-dione.

\begin{tabular}{|c|c|c|}
\hline Atom No. & $\begin{array}{c}\text { APT Chemical shift } \\
(\delta)\end{array}$ & $\begin{array}{c}{ }^{1} \text { H-NMR Chemical shift } \\
(\delta)\end{array}$ \\
\hline \multicolumn{3}{|c|}{ 1,6-heptadiene-3,5-dione moiety } \\
\hline 1,7 & 140.2 & $7.52(2 \mathrm{H}, \mathrm{d}, J=15.6 \mathrm{~Hz})$ \\
\hline 2,6 & 122.3 & $6.43(2 \mathrm{H}, \mathrm{d}, J=15.6 \mathrm{~Hz})$ \\
\hline 3,5 & 183.2 & -- \\
\hline 4 & 101.5 & $5.75(1 \mathrm{H}, \mathrm{s})$ \\
\hline \multicolumn{3}{|c|}{ bis-(4-hydroxy-3-methoxyphenyl) moiety } \\
\hline 1 & 129.0 & -- \\
\hline 2 & 110.4 & \multirow{5}{*}{$\begin{array}{c}7.02-7.08(6 \mathrm{H}, \mathrm{m}, \\
\left.\mathrm{H} 2^{`} / 5^{`} / 6^{\prime}\right)\end{array}$} \\
\hline 3 & 149.3 & \\
\hline 4 & 149.6 & \\
\hline 5 & 113.6 & \\
\hline 6 & -- & \\
\hline $3^{`}-\mathrm{OCH}_{3}$ & 55.9 & $3.86(6 \mathrm{H}, \mathrm{s})$ \\
\hline $\mathrm{OH}$ & -- & -- \\
\hline \multicolumn{3}{|c|}{ Two triazole rings } \\
\hline $4 "$ & -- & -- \\
\hline $5 "$ & 122.5 & $8.12(2 \mathrm{H}, \mathrm{s})$ \\
\hline \multicolumn{3}{|c|}{ Two acetophenone moieties } \\
\hline $1^{\cdots}$ & 137.0 & -- \\
\hline $2^{\prime \prime}, 6^{\prime \prime}$ & 120.2 & $7.79(4 \mathrm{H}, \mathrm{d}, J=8.4 \mathrm{~Hz})$ \\
\hline $3 \cdots, 5 \cdots$ & 130.2 & $8.05(4 \mathrm{H}, \mathrm{d}, J=8.4 \mathrm{~Hz})$ \\
\hline $4 \cdots$ & 139.9 & -- \\
\hline $7 \cdots(\mathrm{C}=0)$ & 196.6 & -- \\
\hline $8 \cdots\left(\mathrm{CH}_{3}\right)$ & 26.7 & $2.59(6 \mathrm{H}, \mathrm{s})$ \\
\hline \multicolumn{3}{|c|}{ Methylene bridges } \\
\hline $7^{`} \mathrm{O}-\mathrm{CH}_{2}$ & 62.8 & $5.35(4 \mathrm{H}, \mathrm{s})$ \\
\hline
\end{tabular}

Table 3: ${ }^{1} \mathrm{H}-\mathrm{NMR}$ and APT spectra of curcumin-acetophenone triazole $\mathbf{C 4}^{\text {a }}$

${ }^{a}$ In $\left(\mathrm{CDCL}_{3}\right)$, at $400 \mathrm{MHz}$ for ${ }^{1} \mathrm{H}-\mathrm{NMR}$, at $100 \mathrm{MHz}$ for APT, Coupling constants ( ) are in $\mathrm{Hz}$.

Amylase inhibitory activity

The prepared triazoles have been evaluated for their alphaamylase inhibitory activity using quercetin as a standard drug. Inhibitory effects are presented in table 4. Curcumin-benzyl triazole derivative (C2) was found to exhibit strong $\alpha$-amylase inhibitory activity $(83.96 \%)$. 


\begin{tabular}{|c|c|}
\hline Compounds Conc. $\mathbf{1 ~ m g / m l}$ & Inhibition\% \\
\hline Quercetin & 67.9 \\
\hline C1 (curcumin) & 20.5 \\
\hline C2 & 83.9 \\
\hline C3 & 43.0 \\
\hline C4 & -2.7 \\
\hline
\end{tabular}

Table 4: The inhibitory effects of curcumin triazoles on $\alpha$-amylase activity.

Docking study of curcumin triazoles against $\alpha$ - amylase binding site

Docking studies were performed to determine binding affinity of curcumin triazoles to $\alpha$ - amylase enzyme. The binding affinities were calculated and presented in table 5 . The lower value showed the more stable complex formed between the ligand and target protein. The docking results are in good agreement of the experimental results. Curcumin-benzyl triazole (C2) which showed high inhibitory activity in the in-vitro assay also possessed high binding affinity to $\alpha$-amylase with low binding energy (-151.9 Kcal/ mol). Molecular models of curcumin-benzyl triazole (C2) docked in the binding site of $\alpha$-amylase, showing the amino acid residues involved in the interaction were presented in (Figure 1).

\begin{tabular}{|l|c|c|c|c|}
\hline \multicolumn{1}{|c|}{ Code } & $\begin{array}{c}\text { Pharma } \\
\text { score }\end{array}$ & $\begin{array}{c}\text { Total } \\
\text { Energy }\end{array}$ & VDW & H-Bond \\
\hline $\begin{array}{l}\text { Acarbose derived } \\
\text { hexasaccharide }\end{array}$ & -255.1 & -197.5 & -142.004 & -55.528 \\
\hline C4 & -141.7 & -138.763 & -124.052 & -14.7115 \\
\hline C2 & -151.9 & -126.454 & -104.401 & -22.0532 \\
\hline C3 & -153 & -112.602 & -78.096 & -34.5057 \\
\hline C1 (curcumin) & -142.8 & -106.689 & -79.8253 & -26.8635 \\
\hline
\end{tabular}

Table 5: Binding energy of compounds docked in the binding site of alpha-amylase.
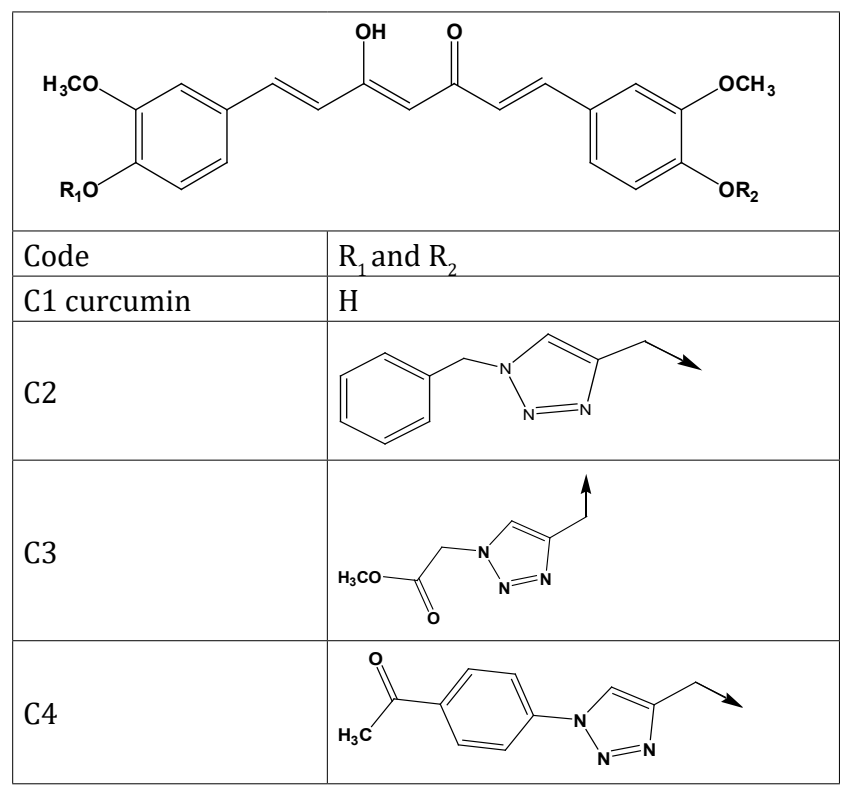

Table 6: Summary of the obtained curcumin triazoles.

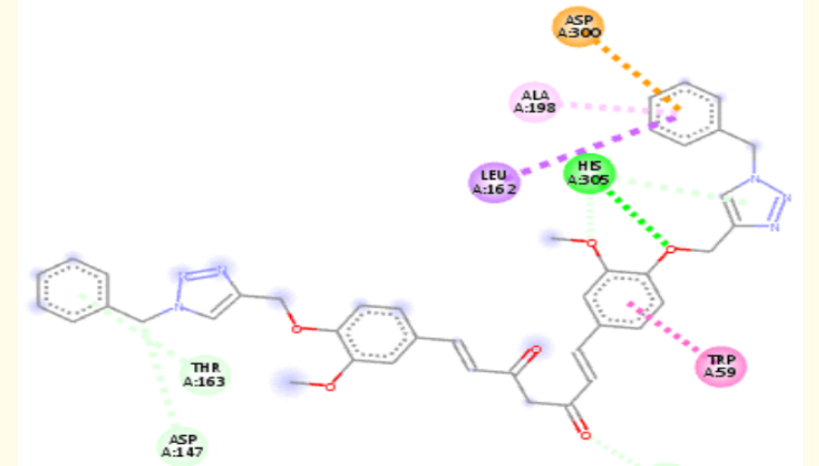

S:LV

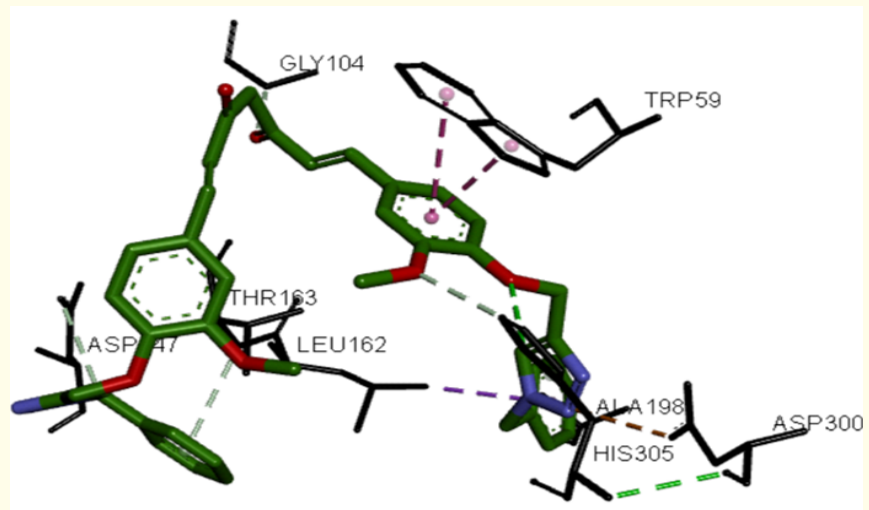

Figure 1: Molecular models of curcumin-benzyl triazole C2 docked in the binding site of $\alpha$-amylase, showing the amino acid residues involved in the interaction (ALA 198, GLY 104, HIS 305, ASP 300, ASP 147, TRP 59, THR 163, LEU 162). Hydrogen bonds (are depicted in green dashed style), Vander waals (light green),

Pi-alkyl interaction (rose), Pi-Pi interaction (pink), Pi-sigma (purple), Pi-ion (orange).

\section{Conclusion}

In this study, three new curcumin-triazole derivatives were synthesized via the CuAAC click reaction. The prepared triazoles were evaluated for their alpha-amylase inhibitory potency. Among the tested compounds, curcumin-benzyl triazole derivative C2 was found to have high inhibitory activity against amylase. Molecular docking studies showed that the prepared triazoles have high binding affinity toward human $\alpha$-amylase (PDBID: 1u30). Thus, curcumin-triazole derivative $\mathrm{C} 2$ can serve as a lead molecule in designing of alpha-amylase inhibitors by further structure optimization.

\section{Bibliography}

1. Cragg GM and Newman DJ. "Natural products: a continuing source of novel drug leads". Biochimica et Biophysica Acta 1830.6 (2013): 3670-3695.

2. Hong JY. "Natural product diversity and its role in chemical biology and drug discovery". Current Opinion in Chemical Biology 15 (2011): 350-354. 
3. Abdel Bar FM., et al. "Design and pharmacophore modeling of biaryl methyl eugenol analogs as breast cancer invasion inhibitors". Bioorganic and Medicinal Chemistry 18.2 (2010): 496-507.

4. Bar FMA., et al. "Rational design and semisynthesis of betulinic acid analogues as potent topoisomerase inhibitors". Journal of Natural Products 72.9 (2009): 1643-1650.

5. Abdel Bar FM., et al. "Derivatization, molecular docking and in vitro acetylcholinesterase inhibitory activity of glycyrrhizin as a selective anti-Alzheimer agent". Natural Product Research 33.18 (2018): 2591-2599.

6. El-Naggar MH., et al. "Synthesis, docking, cytotoxicity, and LTA $4 \mathrm{H}$ inhibitory activity of new gingerol derivatives as potential colorectal cancer therapy". Bioorganic and Medicinal Chemistry 25.3 (2017): 1277-1285.

7. Bayomi SM., et al. "Synthesis and biological evaluation of new curcumin derivatives as antioxidant and antitumor agents". Medicinal Chemistry Research 22.3 (2012): 1147-1162.

8. Tiwari VK., et al. “Cu-Catalyzed Click Reaction in Carbohydrate Chemistry”. Chemical Reviews 116.5 (2016): 3086-3240.

9. Farzaei F., et al. "A mechanistic review on medicinal plants used for diabetes mellitus in traditional persian medicine". Evidence-Based Complementary and Alternative Medicine 22.4 (2017): 944-955.

10. Keerthana G., et al. "In Vitro $\alpha$-amylase inhibitory and anti-oxidant activities of ethanolic leaf extract of Croton bonplandianum". Asian Journal of Pharmaceutical and Clinical Research 6.4 (2013): 32-36.

11. Van de Laar FA., et al. "Alpha-glucosidase inhibitors for patients with type 2 diabetes: results from a Cochrane systematic review and meta-analysis". Diabetes Care 28 (2005): 166175.

12. Derosa G and Maffioli P. "Mini-Special Issue paper Management of diabetic patients with hypoglycemic agents $\alpha$-Glucosidase inhibitors and their use in clinical practice". Archives of Medical Science 5 (2012): 899-906.

13. Kajaria D., et al. "In-vitro $\alpha$ amylase and glycosidase inhibitory effect of ethanolic extract of antiasthmatic drug - Shirishadi". Journal of Advanced Pharmaceutical Technology and Research 4.4 (2013): 206-209.

14. Oyagbemi AA., et al. "Curcumin: from food spice to cancer prevention". Asian Pacific Journal of Cancer Prevention 10.6 (2009): 963-967.

15. Batool T., et al., "A convenient method for the synthesis of (prop-2-ynyloxy) benzene derivatives via reaction with propargyl bromide, their optimization, scope and biological evaluation". PLoS ONE 9.12 (2014) 1-19.

16. Jayasri M., et al. " $\alpha$-amylase and $\alpha$-glucosidase inhibitory activity of Costus pictus D. Don in the management of diabetes". Journal of Herbal Medicine and Toxicology 3.1 (2009): 91-94.
17. Biovia DS. Discovery studio visualizer. San Diego, CA, USA (2017).

18. Lestari MLAD and Indrayanto G. "Curcumin". Profiles of Drug Substances, Excipients and Related Methodology 39 (2014): 113-204.

Volume 3 Issue 11 November 2019

(C) All rights are reserved by Farid A Badria., et al. 